\title{
Characterisation of hardwood fibres used for wood fibre insulation boards (WFIB)
}

\author{
Arne A. P. Imken ${ }^{1} \cdot$ Burkhard Plinke $^{2} \cdot$ Carsten Mai $^{1}$
}

Received: 31 August 2020 / Accepted: 18 March 2021 / Published online: 6 April 2021

(c) The Author(s) 2021

\begin{abstract}
Wood fibre insulation boards (WFIB) are typically made from softwood fibres. However, due to the rapid decrease in softwood stands in Germany, the industry will be forced to adapt to the wood market. Therefore, alternative approaches for the substitution of softwood with hardwood will be needed in the fibre industry. The objective of this paper is to address the characterisation of hardwood fibres regarding their availability for the WFIB industry. The physico-mechanical properties of WFIB are significantly determined by the length of the fibres. Longer softwood fibres usually generate higher strength properties and a lower thermal conductivity than shorter hardwood fibres. In this paper, the potential application of hardwood fibres (up to 20,500 $\mu \mathrm{m}$ long) produced in a refiner by thermo-mechanical pulping (TMP) to WFIB production was examined. The scanner-based system FibreShape was used for the automatic optical analysis of the geodesic length distribution of fibres. The analysed hardwood fibres contained significantly more dust and were shorter than respectively produced softwood fibres, limiting their applicability for WFIB production. Thus, two analytical approaches were chosen to receive longer fibres and less dust: (1) blending hardwood fibres with supporting softwood fibres (20\%, 50 and $80 \%$ proportion of softwood), and (2) mathematical fractionation of hardwood fibres based on the fibre length to remove all particles smaller than $500 \mu \mathrm{m}$. It was concluded that the practical fractionation seems to be economically and ecologically challenging and that blending hardwood fibres with at least $50 \%$ softwood fibres offers a promising approach, which should be further studied.
\end{abstract}

\section{Introduction}

The characterisation of fibres used for fibreboards is difficult because their shape is complex, and their size distribution covers several scales from micrometres up to centimetres. There is no generally accepted procedure to perform such a characterisation. In industrial operations, it is mostly done by means of subjective assessment by experienced workers (Benthien et al. 2014). A mechanical analysis by sieving provides a more objective approach and enhances comparability of obtained data. This is possible, for example, by using a vibrating sieve, a tumbling sieve or an air jet sieve. None of these sieving techniques, however, are suitable for

Arne A. P. Imken

arne.imken@uni-goettingen.de

1 Wood Biology and Wood Products, Faculty of Forestry and Forest Ecology, University of Goettingen, Buesgenweg 4, 37077 Goettingen, Germany

2 Technology for Wood and Natural Fibre-Based Materials, Fraunhofer Institute for Wood Research WKI, Bienroder Weg 54E, 38108 Braunschweig, Germany fibres because they agglomerate to balls and, even if the agglomeration can be avoided, sieving indicates only the width of the particles, not their length (Plinke et al. 2012). In addition, characterisation based on sieving reflects the mass distribution of the fibres fractionated by sieving. This is due to the probability of fibres passing the sieve's meshes, and this probability depends not only on fibre morphology but also on sieving time and air pressure — if an air jet sieve is used.

On the other hand, fibre size distribution can be characterised via optical measurements of their shape characteristics such as length, width and circumference as defined in ISO 9276-6 (2008). Manual optical analysis systems such as digital analysis of microscopic images are error-prone, time consuming, and require analysis of a high number of fibres to fulfil statistical requirements (Plinke et al. 2016). Automatic optical analysis systems, however, are the best methods for fibre characterisation. There are various commercial and semi-commercial systems on the European market such as QICPIC (Sympatec GmbH, Clausthal-Zellerfeld, Germany), Valmet FS5 fibre analyser (Valmet, Espoo, Finland), FibreShape (Innovative Sensor Technology IST 
AG, Vilters, Switzerland) or FibreCube (Johann Heinrich von Thünen-Institut, Hamburg, Germany) based on different measuring technology. All these systems are usable to characterise fibres for production of medium-density fibreboard (MDF), but only FibreShape and FibreCube can analyse fibres for the production of wood fibre insulation board (WFIB) due to the larger size of these fibres. FibreShape is better suited for, e.g., "banana" shapes and especially curled and branched fibres compared with other methods to compute size and shape characteristics. Production of fibres for WFIB is conducted with a wider disc gap during the refining process; this is why this fibre material contains much more fibre bundles and even shives. As previously shown, the systems QICPIC, FibreCube and FibreShape did not provide significantly different results with respect to the characterisation of wood particles to produce wood polymer composites (WPC) (Plinke et al. 2016). On that account, this study focuses on the fibre analyser FibreShape. The representation of particle size distribution by FibreShape is described in the standard ISO 9276-1 (1998), which specifies histograms, density distributions and cumulative distributions. The definition of size parameters of irregular particle geometries is standardized in ISO 9276-6 (2008).

WFIB are usually made of softwood fibres obtained through thermo-mechanical pulping (TMP), where wood chips are treated with superheated steam at high pressure and then defibrillated in a refiner (Lyons 2014). Production proceeds either via a dry or wet process, where today the dry process is applied more frequently. Usually polymeric methylene-diphenyl-isocyanate (PMDI) serves as binder (Vangronsveld et al. 2010). The worldwide production of woodbased panels (WBP) in 2016 amounted to 415,602,000 m², while 8,956,000 $\mathrm{m}^{3}$ thereof fall upon WFIB (FAO 2018). Accordingly, WFIB account for only a small proportion of the global wood products industry but their production is increasing rapidly. For instance, the use of WFIB in Germany has quintupled from 250,000 in 2008 to $1,250,000 \mathrm{~m}^{3}$ in 2010 (Sprengard et al. 2013). The development will continue to increase because of the public environmental awareness and due to the energy saving ordinance, which stipulates efficient insulation of buildings. The combination of the energy saving ordinance and public environmental awareness will lead to an increased utilisation of insulating materials from renewable resources such as WFIB.

As for the whole wood industry, forest restructuring in many European countries is an important challenge for the producers of WFIB. As an example, the area of coniferous stands in Germany has decreased between 2002 and 2012 by about 267,220 hectares and the area of hardwood stands has increased by about 315,368 hectares (Federal Ministry of Food and Agriculture 2015). Hence, researchers are looking for ways to substitute softwoods in wood-based panels with hardwood, including in WFIB. Previous studies have shown that the refiner disc gap and the wood species are the most influencing parameters for fibre length characteristics (Benthien et al. 2017). This indicates the importance of fibre characterisation, especially of hardwood fibres for WFIB.

Hardwood fibres are biologically shorter (average of $1 \mathrm{~mm}$ ) than softwood fibres (average of 3-8 $\mathrm{mm}$ ) (Miller 1999). So far, using hardwoods to produce WFIB has not widely been reported. Bartholme et al. (2009) produced WFIB from beech fibres in a wet process and investigated the mechanical strength properties. Their findings were in line with the results of Eichhorn (2017), who produced WFIB from a blend of softwood and beech fibres, and showed that the addition of beech fibres decreases the mechanical properties and increases the thermal conductivity compared to WFIB solely of softwood.

This study aimed at characterising and comparing TMP fibres of ash, beech, birch, spruce, and blends of these fibres in order to determine their possible usability in WFIB production. Industrial fibres to produce WFIB and spruce fibres to produce MDF were used as references. The results are supposed to show whether a blend of softwood and hardwood fibres and/or a fractionation of the hardwood fibres may enable the usability of hardwood fibres for WFIB production.

\section{Materials and methods}

\subsection{Production of wood fibres}

Apart from the industrial reference fibres, all fibres and blends were produced at Fraunhofer Institute for Wood Research-Wilhelm-Klauditz-Institut (WKI) in Braunschweig, Germany. Respective stems (purchased from Lower Saxony State Forests) were debarked with a peeling knife (Wilh. Schmitt \& Comp. GmbH \& Co. KG, Remscheid, Germany) and split by hand before being chopped in a shredder $(120 \times 400$ H2WT, Klöckner KG, Hirtscheid, Germany) to wood chips. To produce fibre blends, the wood chips were mixed to the targeted composition. The pure chips or their blends were defibrillated in a refiner (Andritz AG, Wien, Austria). The defibration conditions are listed in Table 1.

Table 1 Defibration conditions in the refiner

\begin{tabular}{lll}
\hline Type of fibres & WFIB fibres & MDF fibres \\
\hline Rotation (rpm) & 3000 & 3000 \\
Pressure (bar) & 7.5 & 7.5 \\
Temperature $\left({ }^{\circ} \mathrm{C}\right)$ & 170 & 170 \\
Retention time (min) & 5 & 6 \\
Disc gap (mm) & 0.6 & 0.15 \\
Fibre moisture content $(\%)$ & $15-20$ & 6.5 \\
\hline
\end{tabular}




\subsection{Wood fibre materials}

Various types of fibres, industrial fibres for WFIB, selfmanufactured fibres for MDF as references and self-manufactured fibres for WFIB were used in this study. In total, nine different fibre groups were studied (Table 2). The tested fibres were either made solely from Norway spruce (Picea abies), European ash (Fraxinus excelsior), European beech (Fagus sylvatica) or silver birch (Betula pendula) or were blends of Norway spruce with various hardwood fibre blends in proportions of 20,50 and $80 \%$. The hardwood fibre blends contained equal proportions of the three named hardwoods and were produced by blending of the respective wood chips prior to refiner pulping. Industrially produced (mostly) Norway spruce fibres to produce wood fibre insulation boards (WFIB) served as one reference and were purchased from Homatherm, Berga, Germany.

\subsection{Fibre characterisation}

The various fibre groups were characterised by FibreShape (Innovative Sensor Technology IST AG, Vilters, Switzerland). For every measurement, $0.25 \mathrm{~g}$ of fibres were chosen coincidentally from the middle of the fibre mass so that there was the same chance to include dust, fibres and shives for each measurement. The fibres were dispersed manually on a transparent film of A4 size, and a flatbed scanner in transmitted light mode was used to produce images of the fibres. The fibre dimensions were then assessed by static image analysis of the FibreShape software. The "rectangle model" was used to determine geodesic length and geodesic width for the fibres, as wood fibres usually have a shape factor above 1 (i.e. are longer than wide). This model uses the particle's area (number of pixels belonging to its shape) and circumference (amount of steps needed to circumnavigate the shape) assuming the shape would be a rectangle: length and width derive from the equations for area and circumference applied to rectangles. The theoretical resolution of the used scanner was $21 \mu \mathrm{m} / \mathrm{pixel}$. Although this is the limit of detectability, the reliable measuring range ranges from approx. $100 \mu \mathrm{m}$ (corresponding to particles with a shape of at least 5 pixels) up to $5 \mathrm{~cm}$. The results of particle size analysis were depicted according to DIN ISO 9276-1 (1998), DIN ISO 9276-2 (2014) and DIN ISO 9276-6 (2008). All statistical evaluations rely on the weighting method based on particle area $\left(\mathrm{q}_{2}\right.$ distribution) because this size feature was individually measured for each particle and not computed from a volume model. Although this weighting method does not perfectly reflect the mass distribution of particles by length, it is quite close to it and more reliable than size distributions based on the particle number. Therefore, histograms for the particle length distribution are shown as $\mathrm{q}_{2}$ frequency distributions, and the percentiles of the cumulative frequencies (sum distributions) are $\mathrm{Q}_{2}$ distributions. Two length scales with the same amplitude were used for the characterisation in this study. The first length scale ranged from 0 to $20,000 \mu \mathrm{m}$ fibre length and included all measured objects in the studied fibre groups. This means that fibres longer than $20,000 \mu \mathrm{m}$ were not considered. The second length scale ranged from 500 to $20,500 \mu \mathrm{m}$ in order to exclude the dust from statistical evaluation. This limitation to a specific length range can be considered as "optical fractionation". The full length range of $20,000 \mu \mathrm{m}$ was subdivided into 50 fractions of $400 \mu \mathrm{m}$ each: for the first set-up, Fraction 1 included all particles from 0 to $400 \mu \mathrm{m}$, and Fraction 2 included all particles from 400 to $800 \mu \mathrm{m}$, etc.; for the second set-up, Fraction 1 included all particles from 500 to $900 \mu \mathrm{m}$, and Fraction 2 included all particles from 900 to $1300 \mu \mathrm{m}$, etc.

\section{Results and discussion}

\subsection{Characterisation of single-species fibres}

The geodesic length percentiles of the six single-species fibre groups (Table 2) were analysed using FibreShape and presented with respect to the cumulative frequency of the fibre-length-distribution and the percentage distribution within the 50 fractions $(400 \mu \mathrm{m})$. When the full range of
Table 2 Different fibre groups and abbreviations

\begin{tabular}{ll}
\hline Fibre variation & Abbreviation \\
\hline Industry reference of fibres for WFIB (Homatherm—-mostly Norway spruce) & Industry reference \\
Self-manufactured reference of fibres for MDF (Norway spruce) & 100Spruce_MDF \\
Solely Norway spruce fibres & 100_Spruce \\
Solely European ash fibres & 100_Ash \\
Solely European beech fibres & 100_Bech \\
Solely silver birch fibres & 100_Birch \\
A blend of $80 \%$ Norway spruce and 20\% of hardwood blends & 80SW_20HW \\
A blend of 50\% Norway spruce and 50\% of hardwood blends & 50SW_50HW \\
A blend of 20\% Norway spruce and 80\% of hardwood blends & 20SW_80HW \\
\hline
\end{tabular}


particle length was considered (including dust particles), it became obvious that the hardwood fibre groups contained much higher particle numbers and higher percentages in the small fractions (Figs. 1 and 2). As an example, 50\% of all ash ("100_Ash") fibre particles exhibited a length in the range of $0-800 \mu \mathrm{m}$ (Fraction 1 and Fraction 2). In contrast, the lower $50 \%$ of the "Industry reference" particles ranged from 0 to $2400 \mu \mathrm{m}$ (Fractions 1-6), while Fraction 1 and Fraction $2(0-800 \mu \mathrm{m})$ made up only $23 \%$ of the total particle number. Previous studies indicated larger proportions of short fibres in hardwood fibre materials for MDF production compared to softwood fibres. This resulted in a higher bulk density of the hardwood fibre material (Park et al. 2001). Ohlmeyer et al. (2015) pointed out that the mean fibre length of pine TMP fibres was three times as large as that of beech TMP fibres. The geodesic length percentiles of the single-species fibre groups and the references (Table 3 ) indicated that the median values (50\% percentiles) for the softwood fibres ("100_Spruce", "Industry reference" and "100Spruce_MDF") were higher than those for the

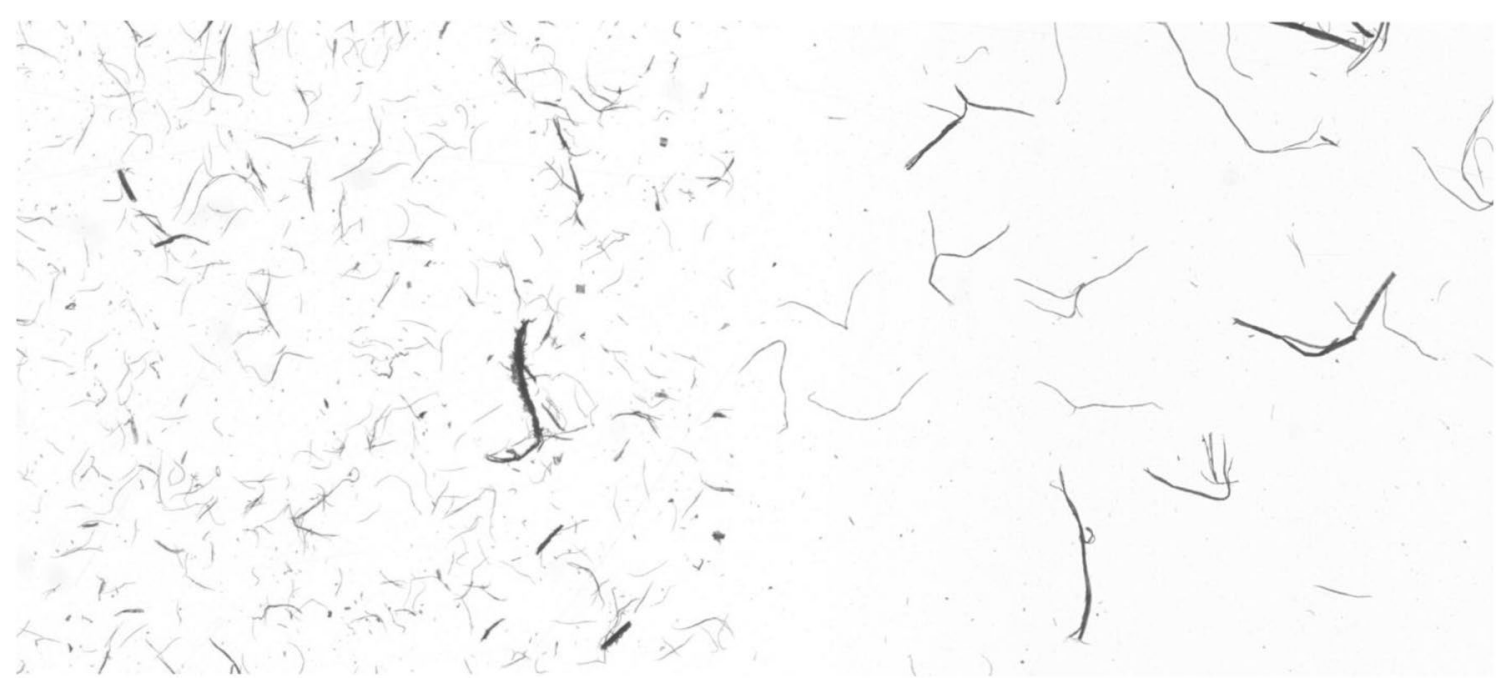

Fig. 1 Scanned particles of single-species ash fibres ("100_Ash") on the left side and the industry reference on the right side

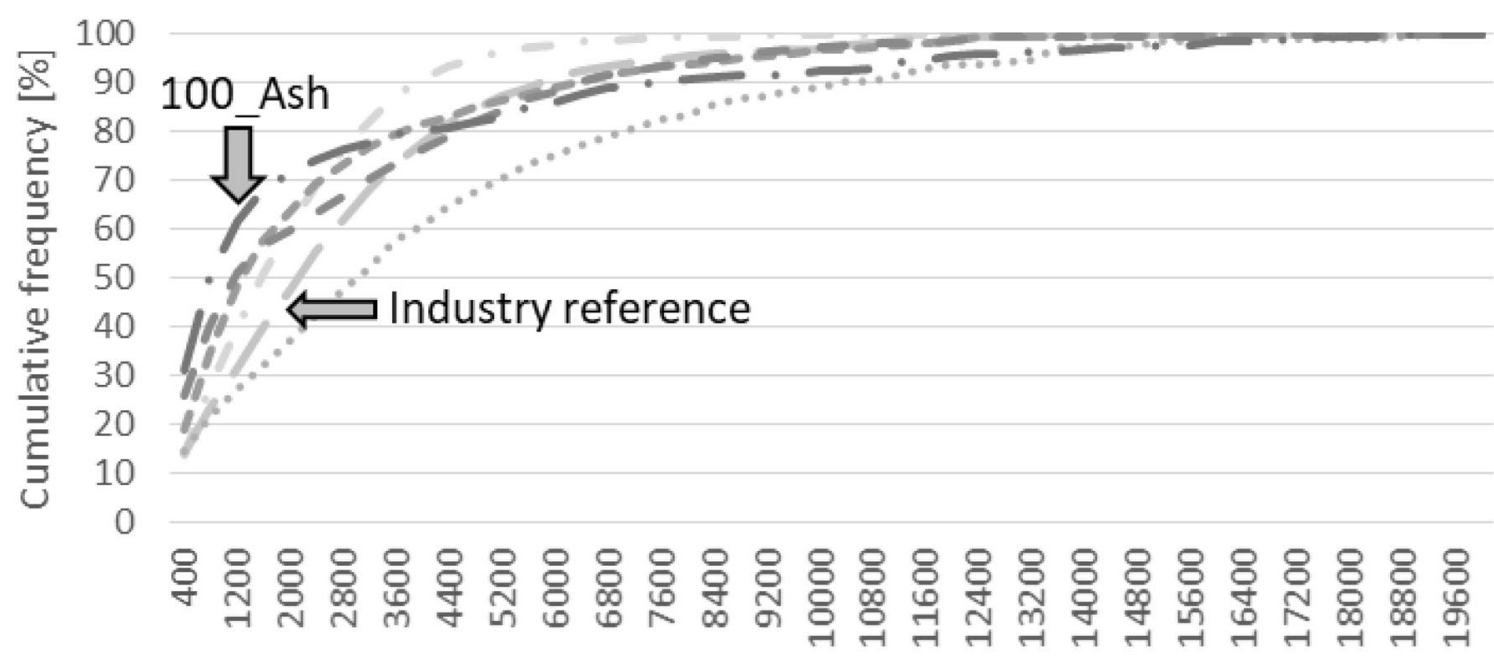

Fibre length $[\mu \mathrm{m}]$

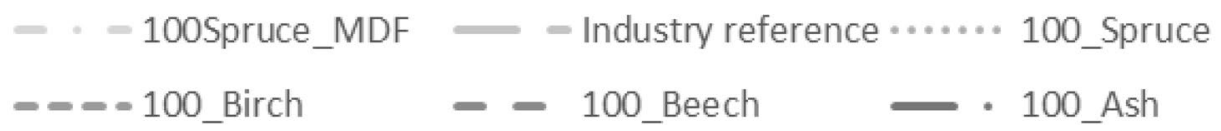

Fig. 2 Cumulative frequency of the fibre-length-distribution for the single-species fibre assortments and the references 
hardwoods ("100_Beech", "100_Birch" and "100_Ash"). "100_Spruce" was even more than three times as large as "100_Ash". There were also differences between the studied hardwoods. "100_Ash" exhibited the highest proportion of small particles $(31 \%, 0-400 \mu \mathrm{m})$, which was higher than for "100_Beech" $(26 \%, 0-400 \mu \mathrm{m})$ and "100_Birch" $(19 \%, 0-400 \mu \mathrm{m})$. "100_Spruce" $(15 \%, 0-400 \mu \mathrm{m})$ was similar to the "Industry reference" $(14 \%, 0-400 \mu \mathrm{m})$ and to "100Spruce_MDF" (14\%, 0-400 $\mu \mathrm{m})$ (Fig. 3).

Moreover, there were differences in the larger fractions. The geodesic length of the fibres "100Spruce_MDF", which were produced with the smaller refiner disc gap, reached almost up to Fraction $24(\leq 9600 \mu \mathrm{m})$; only $0.4 \%$ were above this fraction. "100_Spruce", produced with a larger disc gap for WFIB, exhibited $11.7 \%$ of all fibres above Fraction $24(\leq 9600 \mu \mathrm{m})$. The $90 \%$ percentile $(10,178 \mu \mathrm{m})$ was 2.6 times longer than that of "100Spruce_MDF" $(3853 \mu \mathrm{m})$. The "Industry reference" showed the most uniform length distribution with only $3.2 \%$ of all fibres above Fraction 24 $(\leq 9600 \mu \mathrm{m})$ and a rather small $90 \%$ percentile of $5752 \mu \mathrm{m}$ geodesic length. Even though "100_Ash" had the highest proportion of small particles, it also comprised a relatively high proportion of long particles; $8.3 \%$ of all fibres were above Fraction 24 (3.4\% for "100_Beech" and 4.2\% for "100_Birch") and the 90\% percentile displayed the second largest value of $7480 \mu \mathrm{m}$ (Table 3).

The results generally indicated a higher proportion of particles with length below $400 \mu \mathrm{m}$ in fibre materials from hardwoods than from softwoods. These low-length fractions can be defined as dust. Depending on the hardwood species, there was significantly more dust ("100_Ash" and
Table 3 Geodesic length percentiles $(\mu \mathrm{m})$ of various single-species fibre groups and the references

\begin{tabular}{lllc}
\hline Variation & $10 \%$ percentile & 50\% percentile & $90 \%$ percentile \\
\hline 100Spruce_MDF & 298 & 1542 & 3853 \\
Industry reference & 259 & 2110 & 5752 \\
100_Spruce & 256 & 3012 & 10,178 \\
100_Birch & 189 & 1264 & 6314 \\
100_Beech & 110 & 1138 & 6359 \\
100_Ash & 117 & 792 & 7498 \\
\hline
\end{tabular}

“100_Beech") or slightly more dust ("100_Birch"). WFIBs require high proportions of long fibres and low dust proportions to obtain high strength properties and minimise consumption of adhesive (Benthien et al. 2015). One approach to reach this objective was to use a blend of hardwood and softwood fibres, while another strategy was to fractionate the hardwood fibres and to use only the long-fibre fractions.

\subsection{Characterisation of the blended fibre groups}

Various fibre blends of four wood species-Norway spruce and three hardwoods (ash, beech, birch) were produced by blending the respective wood chips prior to thermo-mechanical pulping (TMP) in a pilot-scale refiner. This approach was chosen because blends of softwood and hardwood assortments are likely to be used for future industrial production of fibreboards in Central Europe. The obtained fibre blends were compared with the references (Figs. 4 and 5). Three fibre blends were produced (Table 2), in which the

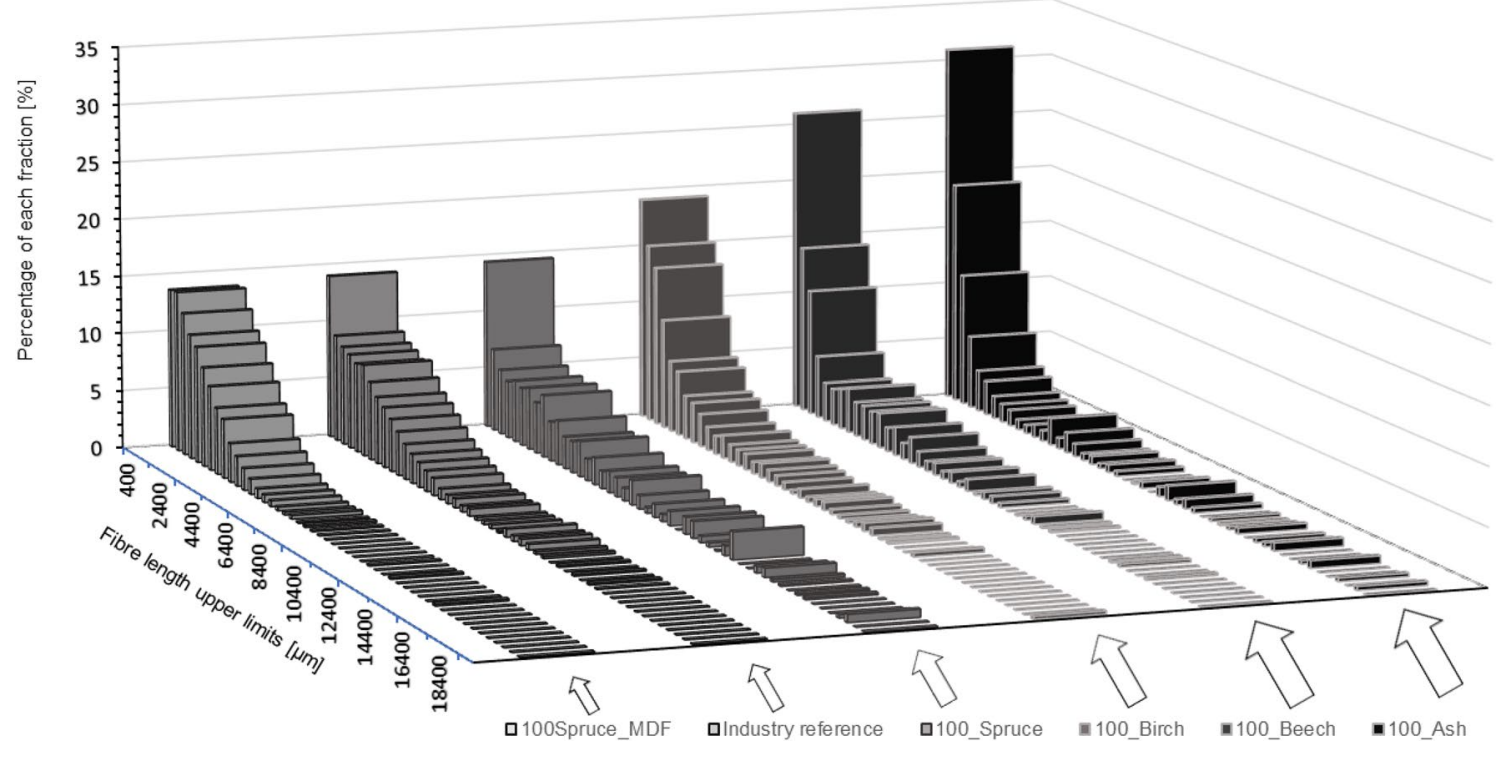

Fig. 3 Percentage of the different fractions ( $400 \mu \mathrm{m}$ range each) of the fibre-length-distribution for the single-species fibre groups and the references 


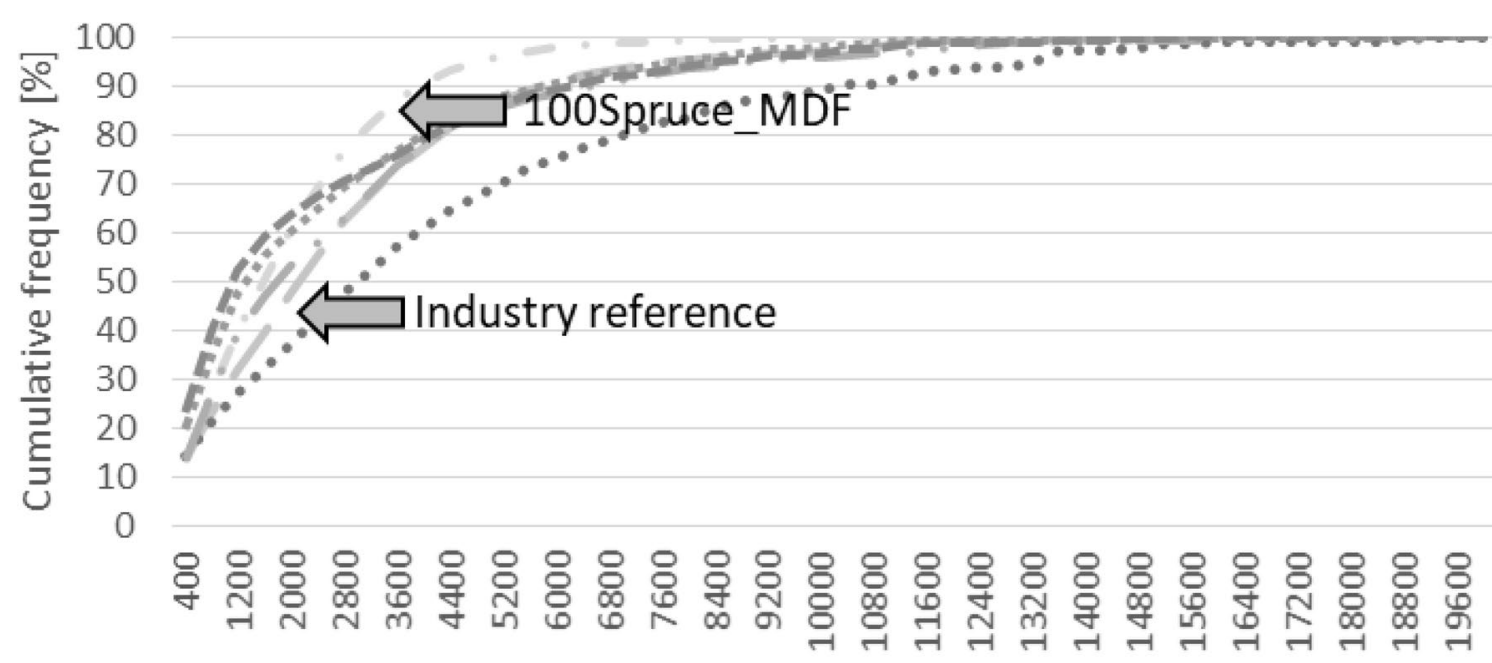

Fibre length $[\mu \mathrm{m}]$

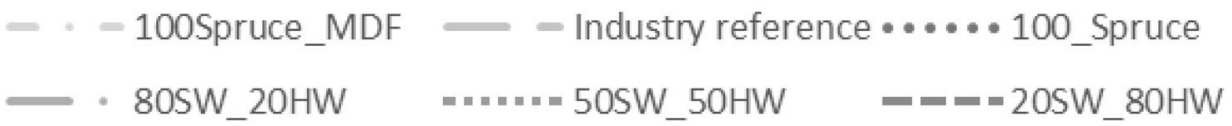

Fig. 4 Cumulative frequency of the fibre-length-distribution for the blended groups and the references

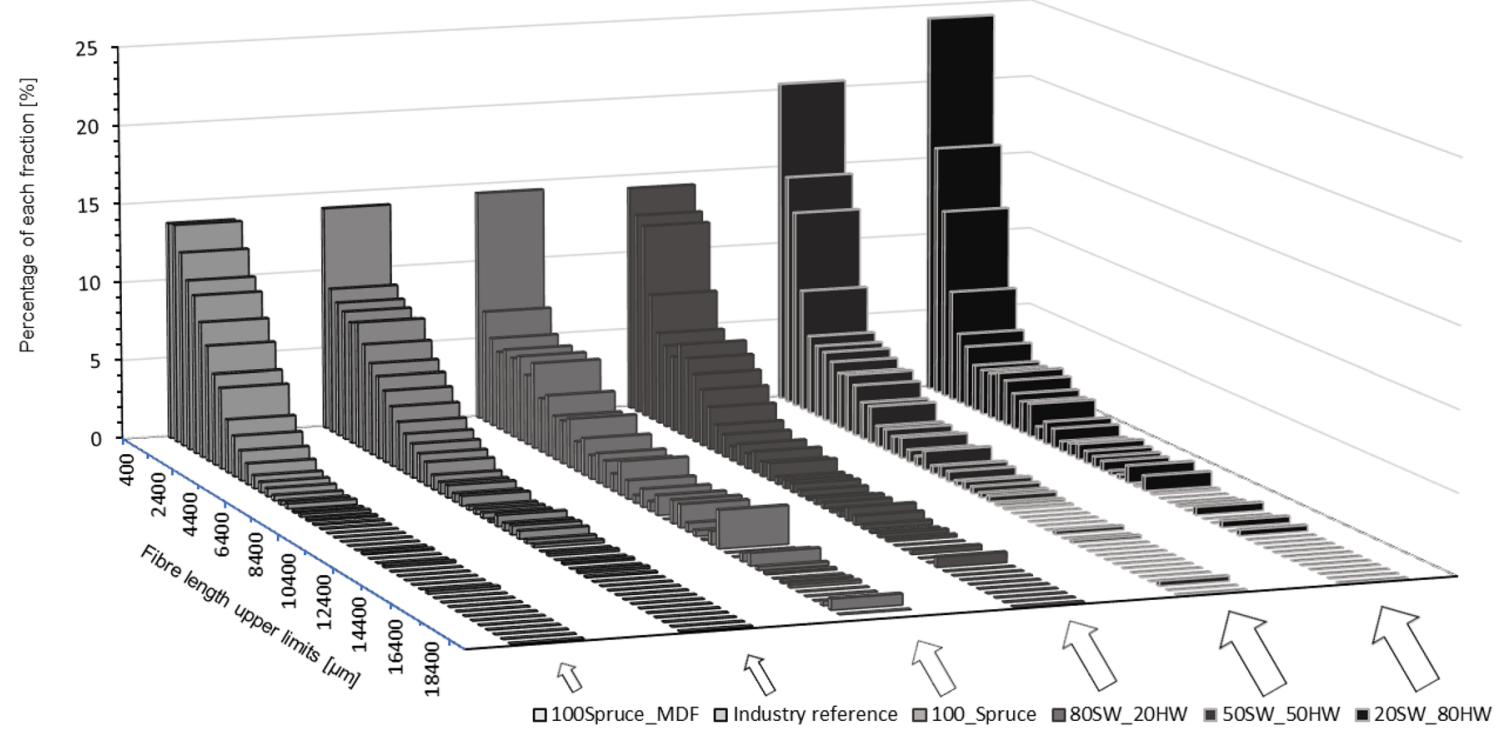

Fig. 5 Percentage of the different fractions ( $400 \mu \mathrm{m}$ range each) of the fibre-length-distribution for the blended groups and the references

hardwood fibre blends contained equal proportions (33\%) of ash, beech and birch.

Previously, a blend of $75 \%$ softwood fibres and $25 \%$ birch fibres was characterised via vibrating sieve by Park et al. (2001). The fibre length distribution was an intermediate between softwood and hardwood fibres. In contrast to this result, in the present study the proportion of Fraction 1 $(\leq 400 \mu \mathrm{m})$ did not change due to adding $20 \%$ of hardwood fibres. The proportion of Fraction 1 amounted to $14 \%$ for the references ("100Spruce_MDF" and "Industry reference") as well as for the "80SW_20HW" group (Fig. 4). Still, the fibre length displayed an intermediate distribution in higher fractions (Fractions $>1$ ). For the "Industry reference", the length of half (50\%) of all fibres ranged up to $2400 \mu \mathrm{m}$; the lower half of the "80SW_20HW" group ranged up to $2000 \mu \mathrm{m}$. 
A comparison of the percentile values of the geodesic length distributions revealed a decreasing median of the groups' fibre length with increasing proportion of hardwood fibres (Table 4). A proportion of only $20 \%$ hardwood fibres lowered the median length compared to the " $100_{-}$ Spruce" group almost to half. The group "50SW_50HW" exhibited the lowest $90 \%$ percentile of all fibre blends with $5794 \mu \mathrm{m}$, which was similar to that of the "Industry reference" $(5752 \mu \mathrm{m})$. The group "80SW_20HW" reached the highest value for the $90 \%$ percentile with $6656 \mu \mathrm{m}$, which was slightly higher than the $90 \%$ percentiles of "100_Beech" and "100_Birch", slightly lower than the $90 \%$ percentile of "100_Ash" and much lower than the $90 \%$ percentile of "100_Spruce" (Tables 3 and 4).

To characterise the long-fibre fractions, Fraction 24 $(\leq 9600 \mu \mathrm{m})$ was exemplarily chosen as the highest fraction occurring in all groups. None of the three fibre blends

Table 4 Geodesic length percentiles $(\mu \mathrm{m})$ of various blended fibre groups and references

\begin{tabular}{llll}
\hline Variation & $10 \%$ percentile & 50\% percentile & $90 \%$ percentile \\
\hline 100Spruce_MDF & 297.9 & 1541.7 & 3852.5 \\
Industry reference & 259.2 & 2110.4 & 5752 \\
100_Spruce & 256.3 & 3012.2 & 10177.7 \\
80SW_20HW & 265.8 & 1779.7 & 6655.5 \\
50SW_50HW & 160.1 & 1313.7 & 5793.7 \\
20SW_80HW & 133.3 & 1111.6 & 6250.9 \\
\hline
\end{tabular}

exhibited considerable proportions above this fraction (between 2 and 4\%) (Fig. 5). Insulation boards with blends of $25 \%, 50$ and $75 \%$ of softwood fibres and $75 \%, 50$ and $25 \%$ of beech fibres, respectively, displayed significantly decreasing strength properties for panels containing $75 \%$ beech fibres (Eichhorn 2017). The author, however, did not characterise the fibre length.

\subsection{Characterisation of fractionated fibre groups}

To exclude dust particles from the fibre material, an optical fractionation was conducted via FibreShape (Figs. 6 and 7). Referring to Blecken (2004), dust is defined as particles smaller than $500 \mu \mathrm{m}$ and the range for analysis was therefore set from 500 to $20,500 \mu \mathrm{m}$. After the fractionation, the hardwood materials still contained higher proportions of the small fractions than the material based on softwood. For example, in "100_Ash", 50\% of all fibres were in Fraction 1,2 and $3(500-1700 \mu \mathrm{m})$, while the lower $50 \%$ of all fibres in the "Industry reference" ranged up to Fraction 6 (500-2900 $\mu \mathrm{m})$ (Fig. 6).

As observed for the analysis in Figs. 3 and 5, the highest proportion of fibres analysed by fractionation was found in Fraction $1(\leq 900 \mu \mathrm{m})$; for example, in "100_Ash", Fraction 1 made up $28 \%$. In other cases, the ratios changed compared to the previous analysis (Figs. 3 and 5), for example, Fraction 1" of 100_Birch" contained as many fibres as "100_Beech" (20\% each) (Fig. 7). The median of the fractionated groups without dust (Fig. 7) was clearly higher than that of the
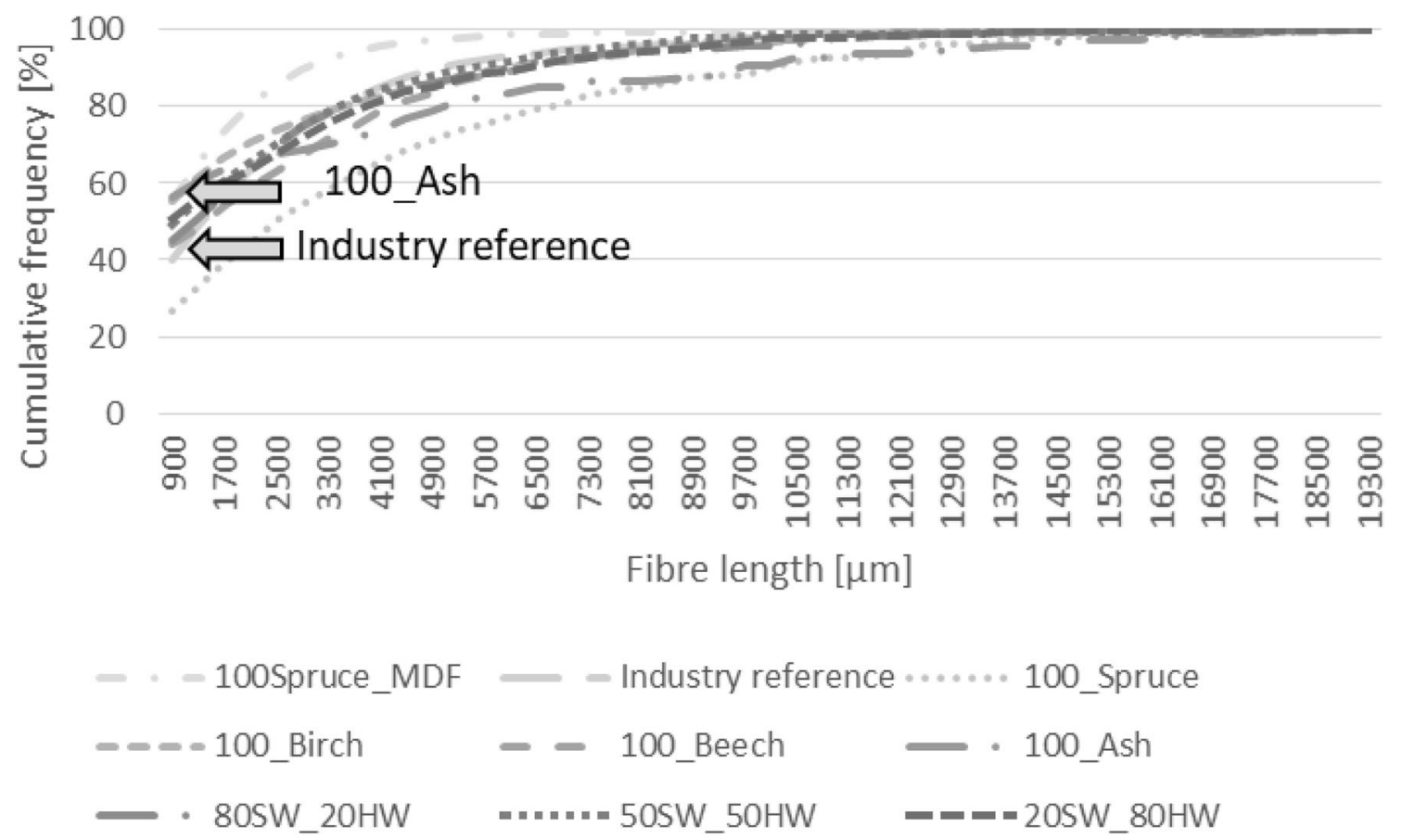

Fig. 6 Cumulative frequency of the fibre-length-distribution for all groups after optical fractionation 


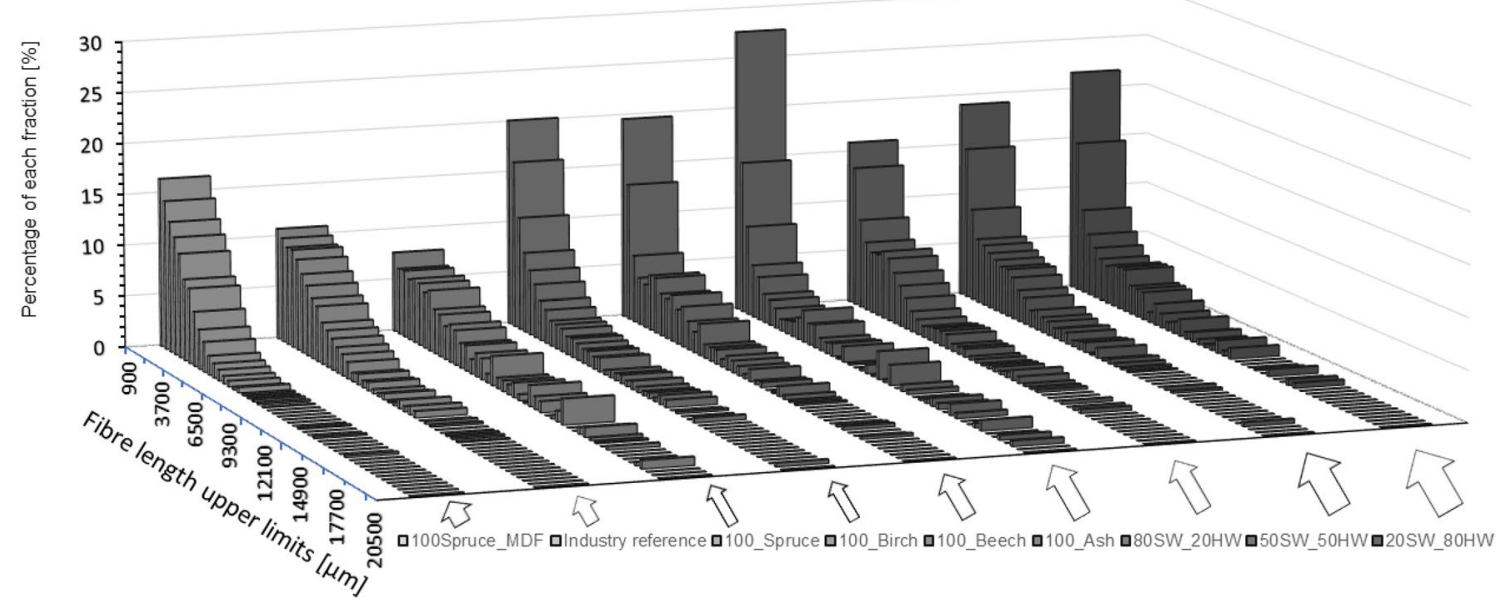

Fig. 7 Percentage of the different fractions ( $400 \mu \mathrm{m}$ range each) for the fibre-length-distribution for all groups after optical fractionation

Table 5 Comparison of the geodesic length median $(\mu \mathrm{m})$ value with and without dust (fractionation)

\begin{tabular}{lll}
\hline Variation & $\begin{array}{l}\text { Median }(\mu \mathrm{m}) \text { with } \\
\text { dust }\end{array}$ & $\begin{array}{l}\text { Median }(\mu \mathrm{m}) \\
\text { without dust }\end{array}$ \\
\hline 100Spruce_MDF & 1542 & 1912 \\
Industry reference & 2110 & 2553 \\
100_Spruce & 3012 & 3675 \\
100_Birch & 1264 & 1829 \\
100_Beech & 1138 & 2614 \\
100_Ash & 792 & 1620 \\
80SW_20HW & 1780 & 2435 \\
50SW_50HW & 1314 & 2147 \\
20SW/80HW & 1112 & 2044 \\
\hline
\end{tabular}

respective non-fractionated groups (Figs. 3 and 5) including dust (Table 5). The medians of "100_Ash" and "100_ Beech" were more than twice as high after the fractionation, while the median of the references only increased by $21 \%$
("Industry reference") to $24 \%$ ("100Spruce_MDF") due to fractionation. For the blended groups, increasing proportions of hardwood fibres resulted in an increasing difference in the median obtained by full-range and by fractionated analysis. The increase in the median due to fractionation for the group " $80 \mathrm{SW} / 20 \mathrm{HW}$ " amounted only to $37 \%$, for the group "50SW/50HW" to $63 \%$ and for the group " $20 \mathrm{SW} / 80 \mathrm{HW}$ " to $84 \%$. This indicated that increasing proportions of dust were due to increasing proportions of hardwood.

Another analytical option was to assess the length distribution based on the particle number without weighting by area $\left(\mathrm{q}_{0}\right.$ distribution). This approach only compared the relative change of the particle number, because absolute numbers do not reflect the mass distribution as in weighted (q2-) distributions. However, the results (Table 6) were similar to the ones from Table 5 as fractionation had comparable effects on the percentage reduction in particle number and increase in the median. As an example, in case of the fractionated groups "100_Ash" and "100_Beech", the particle numbers exhibited the largest decreases by
Table 6 Particle number of the fibre groups without and after fractionation

\begin{tabular}{lccl}
\hline Variation & $\begin{array}{l}\text { Particle number without } \\
\text { fractionation }\end{array}$ & $\begin{array}{l}\text { Particle number after frac- } \\
\text { tionation }(>0.5 \mathrm{~mm})\end{array}$ & $\begin{array}{l}\text { Relative decrease of } \\
\text { the particle number } \\
(\%)\end{array}$ \\
\hline 100Spruce_MDF & 96,703 & 33,070 & 66 \\
Industry reference & 87,951 & 23,172 & 74 \\
100_Spruce & 37,682 & 7635 & 80 \\
100_Birch & 96,693 & 24,067 & 75 \\
100_Beech & 137,666 & 19,553 & 86 \\
100_Ash & 105,604 & 16,812 & 84 \\
80SW_20HW & 151,461 & 29,268 & 81 \\
50SW_50HW & 114,856 & 26,349 & 77 \\
20SW/80HW & 95,670 & 29,543 & 69 \\
\hline
\end{tabular}


approximately 84 and $86 \%$ compared to the numbers for the non-fractionated groups. The smallest decrease of $66 \%$ was observed for "100Spruce_MDF". For the blended groups, the largest decrease in the particle number was found at the highest hardwood content ("20SW_80HW"). Abubakr et al. (1994) reported that practical fibre fractionation for papermaking resulted in enhanced strength indexes. The authors attributed this to a significant proportion of higher-grade papermaking fibres in the long-fibre fraction detected in a Kajaani fibre analyser (today: Valmet Fibre Image Analyser). For wood-polypropylene composites, fractionated longer fibres showed the highest reinforcing potential due to the larger aspect ratio and higher single fibre character (Horbens et al. 2012). Fractionation, however, is time consuming, expensive and leads to a huge amount of small fibres waste material. For example, approximately one-third of all fibres in "100_Ash" would be sorted out due to fractionation. Discarding this material would be an economic and ecologic aberration. Alternative usage of the dust is necessary; utilisation in wood-plastic composites (WPC), for pellets production, or as fuel might be a potential option. No in-depth studies on mechanical and insulation properties of WFIB containing hardwood fibres have been reported so far. Subsequent studies on the production of WFIB shall compare the mechanical strength properties and the thermal conductivity of WFIB produced from blends of hardwood and softwood fibres as well as fractionated hardwood fibres.

\section{Conclusion}

The optical characterisation of single fibre assortments and fibre blends for WFIB reveals that hardwood fibre materials contain distinctly more dust than respective softwood fibre materials. Accordingly, the median length of hardwoods is lower, even lower than the median of the length of softwood MDF-fibres. Furthermore, the softwood fibres for WFIB are twice as long as softwood fibres for MDF. The higher dust content and lower median length of hardwood fibres make their utilisation for WFIB production more difficult, as WFIB requires low dust content and long fibres for successful production. Blends of softwood and hardwood fibres show a fibre length distribution intermediate between softwood and hardwood fibres when adding at least $50 \%$ of softwood fibres to the hardwood fibre blends. This can be an appropriate method for the usage of hardwood fibres for WFIBs. Fractionated hardwood fibres show less dust proportions, as those are mathematically removed from the samples. This suggests that fractionation might be a valid method to introduce hardwood in WFIB production.
Acknowledgements The authors are grateful for financial support in the frame of the project "GerLau" (22015615) by Fachagentur für Nachwachsende Rohstoffe e.V. (FNR).

Funding Open Access funding enabled and organized by Projekt DEAL.

\section{Declarations}

Conflict of interest The authors declare no conflicts of interest.

Open Access This article is licensed under a Creative Commons Attribution 4.0 International License, which permits use, sharing, adaptation, distribution and reproduction in any medium or format, as long as you give appropriate credit to the original author(s) and the source, provide a link to the Creative Commons licence, and indicate if changes were made. The images or other third party material in this article are included in the article's Creative Commons licence, unless indicated otherwise in a credit line to the material. If material is not included in the article's Creative Commons licence and your intended use is not permitted by statutory regulation or exceeds the permitted use, you will need to obtain permission directly from the copyright holder. To view a copy of this licence, visit http://creativecommons.org/licenses/by/4.0/.

\section{References}

Abubakr SM, Scott GM, Klungness JH (1994) Fiber fractionation as a method of improving handsheet properties after repeated recycling. Tappi J 78(5):123-126

Bartholme B, Avramidis G, Viöl W, Kharazipour A (2009) Herstellung von organisch gebundenen Holzfaser-Dämmplatten aus Buchenholz. [Manufacture of organically bound wood fiber insulation boards from beech wood]. Holztechnologie 50(1):23-26

Benthien JT, Heldner S, Seppke B, Bähnisch C, Ohlmeyer M (2014) Innovativer Ansatz zur Bestimmung der Faserlänge. Automatisierte und reproduzierbare Methode zur Vermessung von Faserstoff entwickelt. [Innovative approach to determining fibre length. Automated and reproducible method for measuring pulp developed]. Holz-Zentralblatt 140(41):1000

Benthien JT, Heldner S, Ohlmeyer M, Bähnisch C, Hasener J, Seidl C, Pfemeter A, Kathmann C (2015) Untersuchung der Faserqualität von TMP für die MDF-Produktion. Abschlussbericht zum FNRVorhaben "Fiber-Impact" (FKZ: 22013211). [Investigation of the fiber quality of TMP for MDF production. Final report on the FNR project "Fiber Impact" (FKZ: 22013211)]. Thünen Report, Braunschweig

Benthien JT, Heldner S, Ohlmeyer M (2017) Investigation of the interrelations between defibration conditions, fiber size and medium-density fiberboard (MDF) properties. Eur J Wood Prod 75(2):215-232.

Blecken J (2004) Optimierung der Staub- und Späneerfassung in stationären Holzbearbeitungsmaschinen. [Optimization of dust and chip collection in stationary woodworking machines]. Dissertation, Carolo-Wilhelmina zu Braunschweig

Eichhorn SC (2017) Entwicklung neuartiger mit Polyurethan gebundener Holzfaserdämmstoffe geringer Rohdichte. [Development of novel polyurethane bonded wood fibre insulation materials of low density]. Dissertation, Georg-August-Universität Göttingen

FAO (2018) FAO yearbook of forest products 2016. Food \& Agriculture Org, Rome 
Federal Ministry of Food and Agriculture (2015) Dritte Bundeswaldinventur. https://bwi.info. Accessed 05 May 2020

Horbens M, Pfriem A, Ganster J, Wagenführ A (2012) Holzfasern als Verstärkungsfasern in Holz-Polypropylen-Verbundwerkstoffen. [Wood fibres as reinforcing fibres in wood-polypropylene composites]. Holztechnologie 53(6):21-25

ISO 9276-1 (1998) Representation of results of particle size analysisPart 1: Graphical representation. International Organization for Standardization, Switzerland

ISO 9276-6 (2008) Representation of results of particle size analysis-Part 6: Descriptive and quantitative representation of particle shape and morphology. International Organization for Standardization, Switzerland

ISO 9276-2 (2014) Representation of results of particle size analysis-Part 2: Calculation of average particle sizes/diameters and moments from particle size distributions. International Organization for Standardization, Switzerland

Lyons A (2014) Materials for architects and builders, 5th edn. Taylor and Francis, Hoboken

Miller RB (1999) Structure of wood. In: Wood handbook: wood as an engineering material, U.S. Department of Agriculture, Forest Service, Forest Products Laboratory, Madison, WI

Ohlmeyer M, Heldner S, Benthien JT, Seppke B (2015) Effects of refining parameters on fibre quality measured by FibreCube. In: Spear M (ed) Proceedings of the International Panel Products Symposium 2015. Llandudno, Wales, 7-8 October 2015. BioComposites Centre, Bangor, pp 17-25

Park B-D, Kim YS, Riedl B (2001) Effect of wood-fiber characteristics on medium density fiberboard (MDF) performance. J Korean Wood Sci Technol 29(3):27-35
Plinke B, Schirp A, Weidenmüller I (2012) Methoden der Holzpartikelgrößenmessung_-Von der technologischen Fragestellung zur aussagefähigen Statistik. [Methods of wood particle size measurement-from the technological question to meaningful statistics]. Holztechnologie 53(4):11-17

Plinke B, Benthien JT, Krause A, Krause KC, Schirp A, Teuber L (2016) Optische Größenvermessung von Holzpartikeln für die WPC-Herstellung. Vergleich dreier Messverfahren. [Optical size measurement of wood particles for WPC production. Comparison of three measurement methods]. Holztechnologie 57(4):43-50

Sprengard C, Treml S, Holm AH (2013) Technologien und Techniken zur Verbesserung der Energieeffizienz von Gebäuden durch Wärmedämmstoffe. Metastudie Wärmedämmstoffe_ProdukteAnwendungen-Innovationen [Technologies and techniques to improve the energy efficiency of buildings through thermal insulation materials. Metastudy thermal insulation materials-products-applications-innovations], München

Vangronsveld E, Berckmans S, Verbinnen K, van Leeuw C, Bormans C (2010) Isocyanate and total inhalable particulate air measurements in the European wood panel industry. Int J Hyg Environ Health 213(6):475-488

Publisher's note Springer Nature remains neutral with regard to jurisdictional claims in published maps and institutional affiliations. 